\title{
The effect of rehabilitation education program on family caregivers of stroke patients
}

\author{
Bum-Chul Jung, Hyun-Joo Kim* \\ Department of Physical Therapy, Korea National University of Transportation : 61, Daehak-ro, Yonggang-ri, Jeungpyeong-eup, \\ Jeungpyeong-gun, Chungcheongbuk-do, Republic of Korea \\ Email address: \\ Jbc0406@naver.com (Bum-Chul J.), hkim@ut.ac.kr (Hyun-Joo K.) \\ To cite this article: \\ Bum-Chul Jung, Hyun-Joo Kim. The Effect of Rehabilitation Education Program on Family Caregivers of Stroke Patients. Science \\ Journal of Public Health. Vol. 2, No. 4, 2014, pp. 337-341. doi: 10.11648/j.sjph.20140204.25
}

\begin{abstract}
The purpose of this study was to investigate the effects of a rehabilitation education Program for family caregivers of stroke patients and to analyze the effects of their depression and burden. Subjects were recruited in R hospital, located in Gyeonggi-do and the period of the study was from April of 2013 to May of 2013. The subject pool was composed of 32 caregivers. Subjects were randomly assigned to either the experimental or nonintervention control conditions with equal number. Control group was taken conventional physical therapy and experimental group was taken conventional physical therapy with rehabilitation education program. Data was analyzed by Chi-square tests, t-tests and paired t-tests using PASW 18.0. This study shows the following results. First, the results showed that the total score of depression decreased significantly after the rehabilitation education program. Second, the results showed that the total score of burden after rehabilitation education Program decreased significantly. The finding indicates that rehabilitation education program for family with CVA patients was effective for reducing depression and burden. In this study, rehabilitation education program showed more effective and significant impact on reducing depression and burden of family caregivers with stroke patients. Especially, the conventional physical therapy with rehabilitation education program is considered as a more effective method than the therapy without rehabilitation education program.
\end{abstract}

Keywords: Rehabilitation, Education, Program, Stroke, Caregiver

\section{Introduction}

Recently, both people's life average expectancy and the aged population ratio have been increasing due to developed medical technology which improves daily living. The aspect of diseases is being changed with the aging population. According to the statistical office, cerebrovascular disease is the second major cause of death rating 53.2 per 100,000 and as the single organ disease, it is ranked first [1].

After acute stroke, about $15 \sim 20 \%$ of patients are dead. Only $10 \%$ of the patients are completely recovered and the rest $70 \sim 75 \%$ are remained with chronic disorders such as motor, sensory, cognitive, speech impairment depending on the impaired brain part $[2,3]$. Also the onset of stroke would be a serious risk for patients as well as their family, so the ability to take care of the patients is becoming an important aspect of the recovery and rehabilitation $[4,5]$.

After the onset of stroke, $11 \%$ of family members suffer from depression for one year [6]. Depression is a natural and basic reaction against stress. And the reaction is ranged from a normal to abnormal emotional change and could be different from person to person. Beck [7] stated that depression is occurred by the people themselves, their circumstances, and their negative cognitive system for the future. The people who take care of their patients usually suffer a lot of stress, unstableness, and high level of dependency for antipsychotic pharmaceutical preparations. It has been reported that the affective diseases that the caregivers have gone through are anger, grief and depression which is most common among the caregivers [8].

In addition, it is shown that the burden of family caregivers with stroke patients is bigger than that of the family caregivers with chronic disease patients such as dementia, hypertension [9]. Especially there is a large burden on family caregivers of inpatients with speech disorder and paralysis [10].

According to the research conducted on the condition of 
caregivers with stroke patients after 1 year of the outbreak, the nursing process negatively affects caregivers on their social activities, leisure time, and family relationship. The study also indicates that around $28 \%$ of the family caregivers experience deterioration of physical condition and lack of sleep during the first year [11].

In order to reduce the depression and burden of family caregivers with stroke patients, consultations, educations and social aid are essential $[10,12]$. Many studies related to the depression and burden of the family caregivers with stroke patients were conducted. The studies are; The sense of coherence about burden, and depressive symptoms of informal caregivers during the first month of the stroke [13], Burden of the caregivers of patients with acute stroke [14], Burden and health - related quality of life among Japanese stroke caregivers [15], and The effect of emotional and informational support intervention on the stress and depression of primary family caregivers of stroke patients [16]. Actually in clinics, family caregivers ask physical therapists to explain the information of the stroke and teach them how to take care of their family member with stroke. Besides the therapy, family caregivers usually provide exercise to their patients. However, this kind of practice is commonly done without a basic understanding of rehabilitation. So the practice is not effectively linked to the rehabilitation therapy.

This study is to investigate the effect of rehabilitation education program for family caregivers of stroke patients, and to find its effects on the depression and burden of caregivers.

\section{Materials and method}

\subsection{Study Design}

This study is to investigate the effect of rehabilitation education program on family caregivers of stroke patients. An outline of the content of the research plan is given in $<$ Table $1>$.

Table 1. The design of this study.

\begin{tabular}{llll}
\hline & Pre-test & Intervention & Post-test \\
\hline Experimental group & Ya1 & $\mathrm{X}$ & Ya2 \\
Control group & $\mathrm{Yb} 1$ & & $\mathrm{~Tb} 2$ \\
\hline
\end{tabular}

Ya1, Yb1: General Characteristics, CES-D, Burden

$\mathrm{X}$ : Rehabilitation education program

Ya2, Yb2 : CES-D, Burden

\subsection{Participants}

32 family caregivers who agreed with the program for their patients diagnosed as stroke by stroke specialists were included. The patients were hospitalized in the $\mathrm{R}$ hospital in Yong-in, Korea with physical therapy. The patients were randomly divided into 2 groups, a control group and an experimental group and each group consisted of 16 patients. Study participants were selected by the following conditions
(1) Family caregivers who take care of stroke patients

(2) Caregivers able to participate in the rehabilitation program 2 times a week, each for 60 mins

(3) Caregivers who agree with the program

(4) Caregivers who do not take antidepressant drugs

Study participants were excluded by the following conditions

(1) Caregivers without any relationship with the stroke patients

(2) Caregivers with neuropsychiatric problem

\subsection{Instrument}

\subsubsection{Rehabilitation Education Program}

The rehabilitation education program provides family caregivers with education that teaches theoretical information about stroke and actual practice from therapists. This program has been developed by preceding research analysis conducted due to the demand for the education and rehabilitation programs based on clinical practice. And the program and its validity were evaluated and revised by physical therapy professors, physical therapist, stroke specialist doctors. After then, final program was established $<$ Table $2>$.

Table 2. Rehabilitation education program.

\begin{tabular}{|c|c|}
\hline & Main subject \\
\hline $1 \mathrm{wks}$ & Orientation, Pre-test/Understanding of stroke \\
\hline 2 wks & $\begin{array}{l}\text { Prevention and Complications of a stroke/The type and } \\
\text { importance of rehabilitation. }\end{array}$ \\
\hline 3 wks & $\begin{array}{l}\text { Therapeutic apparatus, tools, Transfer/Anatomy, How to } \\
\text { exercise joints and muscles }\end{array}$ \\
\hline 4 wks & Walking and falling/Discussion and post-test \\
\hline
\end{tabular}

\subsubsection{Burden}

The instrument for measuring the feeling of burden was originally established by Zarit [17], Montgomery, Gonyea, and Hooyman [18], Novak and Guest [19].It was modified and revised by Suh and Oh [20] and this study uses the modified version. The questionnaire for the burden of family members consists of 20 questions which are financial part (2 questions), physical part (3 questions), social part (4 questions), dependent part (4 questions), and emotional part (7 questions). The questionnaire is a five-point scale and the score 5 means maximal feeling of burden. The reliability of the questionnaire is Cronbach's alpha $=.86$ [20].

\subsubsection{Depression}

This study used center for epidemiologic studies depression scale(CES-D) as an instrument for measuring depression. CES-D [21] is the response to the questionnaire of the feeling and behavior of the respondents during the previous week. It consists of total 20 questions, depressive emotion (4 questions), positive emotion (4 questions), personal relationship (6 questions), and physical aspect ( 3 questions). The score needed for distinguishing depression is 16 points. The reliability of the questionnaire is Cronbach's alpha $=.89$ [21]. 


\subsection{Procedure}

The procedure of the study consists of 5 stages, pre-investigation, development of education program, preliminary investigation, experimental test, and post investigation. The time period was from April 2013 to May 2013.

\subsubsection{Pre-Investigation}

An education desire was measured by an open-ended questionnaire for the family caregivers of the patients with stroke to develop the rehabilitation education program. As a result of the pre-investigation, the demands of the family caregivers of the stroke patients were prognosis of stroke, basic concept of stroke, ways to take care of the patients, and prevention of recurrence.

\subsubsection{Development of a Rehabilitation Education Program}

The program was developed based on the advanced research related to the education for the family caregivers of stroke patients and open-ended questionnaires for the education desire of the family caregivers. The contents of the program are theoretical education and exercise education directly provided by physical therapists. The program has been revised by a professor of physical therapy and a specialist of stroke patients.

\subsubsection{Preliminary Investigation}

Firstly, the purpose of this program was explained to both experimental and control group. And after getting the agreement from the participants, general characteristics, burden, and depression were measured. The questionnaire was answered directly by the participants and in case of misunderstanding of the questions, the assist of the researchers was provided.

\subsubsection{Experimental Test}

The group with the rehabilitation education program (experimental group)

The rehabilitation education program was done in the physical therapy room of the hospital after the patients' daily routine. The program was provided for 60 minutes a day, 2 times a week during 4 weeks, and total 8 times by the assistance of the physical therapists with have experienced clinical practice for more than 3 years.

General physical therapy (control group)

The control group did not participate in the rehabilitation education program. Only general physical therapy was provided to the control group.

\subsubsection{Post Investigation}

Right after the experimental test, the data was collected by the same measuring tool that had been used in the preliminary investigation except the general characteristics of the subject patients.

\subsection{Data Analysis}

All of the statistical analysis used PASW 18.0 for
WINDOW. The general feature of both groups was analyzed through the homogeneity test by chi-square testing method. Before the procedure of the test, dependent variable was analyzed by using independent sample t-test and the test of normality was done by Kolmorogov-Smirnov test. Significance test of the 2 groups before and after the procedure was analyzed by matching sample t-test. The difference between the two groups after 4 weeks of the test was analyzed by independent sample t-test and all of the statistical level of significance was less than 0.05 .

\section{Result}

Total participants of this study were 32. They were divided into 2 groups, experimental and control group, and each group consisted of 16 participants.

\subsection{Homogeneity Test}

Homogeneity test used chi-square testing method to figure out whether there was a significant difference between the two groups in the general feature. As a result, it has been proven that there was no significant statistical difference $<$ Table $3>$.

Table 3. General Characteristics of family caregivers.

\begin{tabular}{|c|c|c|c|c|c|c|c|c|}
\hline & \multicolumn{3}{|c|}{$\begin{array}{l}\text { Experimental } \\
\text { group }(n=16)\end{array}$} & \multicolumn{3}{|c|}{$\begin{array}{l}\text { Control group } \\
(n=16)\end{array}$} & \multirow[t]{2}{*}{$\chi^{2}$} & \multirow[t]{2}{*}{$p$} \\
\hline & (n) & & $(\%)$ & (n) & & $(\%)$ & & \\
\hline \multicolumn{9}{|l|}{ Sex } \\
\hline Male & 4 & & 25.0 & 5 & & 31.3 & \multirow[t]{3}{*}{.155} & \multirow[t]{2}{*}{.694} \\
\hline Female & 12 & & 75.0 & 11 & & 68.8 & & \\
\hline \multicolumn{8}{|l|}{ Age } & \\
\hline 30 39 & 2 & & 12.5 & 2 & & 12.5 & \multirow{5}{*}{.343} & \multirow{5}{*}{.987} \\
\hline 40 49 & 3 & & 18.8 & 4 & & 25.0 & & \\
\hline $50 \sim 59$ & 7 & & 43.8 & 7 & & 43.8 & & \\
\hline $60 \sim 69$ & 3 & & 18.8 & 2 & & 12.5 & & \\
\hline $70 \sim$ & 1 & & 6.3 & 1 & & 6.3 & & \\
\hline \multicolumn{9}{|c|}{ Education level } \\
\hline $\begin{array}{l}\leq \text { Elementary } \\
\text { school }\end{array}$ & 3 & & 18.8 & 2 & & 12.5 & \multirow{3}{*}{1.467} & \multirow{3}{*}{.833} \\
\hline $\begin{array}{l}\text { Middle-High } \\
\text { school }\end{array}$ & 7 & & 43.7 & 8 & & 50.0 & & \\
\hline$\geq$ College & 6 & & 37.5 & 6 & & 37.5 & & \\
\hline \multicolumn{9}{|c|}{ Relationship of caregiver to patient } \\
\hline Spouse & 11 & & 68.8 & 11 & & 68.8 & \multirow{3}{*}{2.000} & \multirow{3}{*}{.572} \\
\hline Child & 5 & & 31.2 & 4 & & 25.0 & & \\
\hline Other & 0 & & 0 & 1 & & 6.3 & & \\
\hline \multicolumn{9}{|c|}{ Caregiving duration } \\
\hline$\leq 6$ month & 9 & & 56.3 & 10 & & 62.5 & \multirow{3}{*}{.386} & \multirow{3}{*}{.824} \\
\hline $6 \sim 12$ month & 5 & & 31.3 & 5 & & 31.3 & & \\
\hline \multirow[t]{2}{*}{$12 \sim 18$ month } & 2 & & 12.5 & 1 & & 6.3 & & \\
\hline & Mean & \pm & SD & Mean & \pm & SD & $t$ & $P$ \\
\hline $\begin{array}{l}\text { Burden } \\
\text { (scores) }\end{array}$ & 62.06 & \pm & 2.17 & 62.44 & \pm & 2.28 & -0.476 & 0.637 \\
\hline $\begin{array}{l}\text { CES-D } \\
\text { (scores) }\end{array}$ & 22.38 & \pm & 1.36 & 22.44 & \pm & 1.31 & -0.132 & 0.896 \\
\hline
\end{tabular}

In the general feature of the participants, there were 12 female participants $(75 \%)$ in the experimental group and 11 participants $(68.8 \%)$ in the control group. When it comes to the age, there were 7 participants in their fifties $(43.8 \%)$ in 
the experimental group, and also 7 participants $(43.8 \%)$ in the control group. In education level, the number of mid-high school graduates was 7 in the experimental group $(43.8 \%)$, and $8(50 \%)$ in the control group. Considering the relationship between caregivers and patients, there were 11 participants $(68.8 \%)$ of husband-wife relationship in the experimental group and $11(68.8 \%)$ in the control group. Participants with caring period of less than 6 months were about $9(56.3 \%)$ in the experimental group and $10(62.5 \%)$ in the control group.

Independent sample t-test was performed to measure the feeling of burden and depression, but there was no significant difference the sample groups $<$ Table $3>$.

\subsection{Hypothesis Test}

\subsubsection{Burden}

The variation of the feeling of burden for the both groups (4weeks) is on $<$ Table $4>$. In the experimental group, there was a significant decrease, from pre $62.06 \pm 2.17$ to post $58.81 \pm 3.83(\mathrm{p}<.001)$. In the control group, there was an increase but no significant difference, from pre $62.44 \pm 2.22$ to post $62.56 \pm 1.71(\mathrm{p}>.05)$.

There was a significant statistical difference in the comparison between the two groups $(\mathrm{p}<.001)$.

\subsubsection{Depression (CES-D)}

The variation of the depression for the both groups ( 4 weeks) is stated on $<$ Table $4>$. There was a significant decrease in the experimental group, from Pre $22.38 \pm 1.36$ to post $18.75 \pm 1.48(\mathrm{p}<.001)$. In the control group, there was an increase but no significant difference, from pre $22.44 \pm 1.31$ to post $23.06 \pm 1.53(\mathrm{p}>.05)$. There was a significant statistical difference in the comparison between the two groups $(\mathrm{p}<.001)$.

Table 4. The comparison between Experimental group and Control group.

\begin{tabular}{|c|c|c|c|c|c|c|c|c|c|}
\hline & & \multicolumn{3}{|c|}{$\begin{array}{l}\text { Experimental } \\
\text { group }(n=16)\end{array}$} & \multicolumn{3}{|c|}{$\begin{array}{l}\text { Control group } \\
(\mathrm{n}=16)\end{array}$} & \multirow[t]{2}{*}{$t$} & \multirow[t]{2}{*}{$p$} \\
\hline & & Mean & \pm & SD & Mean & \pm & SD & & \\
\hline \multirow{2}{*}{ Burden } & Pre & 62.06 & \pm & 2.18 & 62.44 & \pm & 2.28 & \multirow{2}{*}{4.18} & \multirow{2}{*}{.000} \\
\hline & Post & 58.81 & \pm & 3.83 & 62.56 & \pm & 1.71 & & \\
\hline \multirow{6}{*}{ CES-D } & $t$ & 5.11 & & & -0.25 & & & \multirow{6}{*}{7.48} & \multirow{6}{*}{.000} \\
\hline & $p$ & .000 & & & .806 & & & & \\
\hline & Pre & 22.38 & \pm & 1.36 & 22.44 & \pm & 1.31 & & \\
\hline & Post & 18.75 & \pm & 1.48 & 23.06 & \pm & 1.53 & & \\
\hline & $t$ & 9.97 & & & -1.43 & & & & \\
\hline & $p$ & .000 & & & .173 & & & & \\
\hline
\end{tabular}

\section{Discussion and Conclusions}

The purpose of this study was to investigate how the rehabilitation education program, when provided for 2 times a week (4weeks) and 60mins per day, affect the family caregivers' feeling of burden and depression and to apply the program to the actual clinical practice.

The variation of the feeling of burden significantly decreased in the experimental group after the intervention, but the variation in the control group showed an insignificant increase. In the comparison between both groups, it was shown that there was a significant effect of the program in the experimental group. It was reported in the previous study of Kim and Park [22] that after the training of daily activities of patients, self-care ability was improved and family burden was decreased. The study of Yoo, Jeon and Yang [23] demonstrated that the nursing intervention program was effective at decreasing the feeling of burden. The results of the two previous researches were similar to the result of this study on the effect of the rehabilitation program.

In this study, CES-D was used to measure the variation of the depression. As a result of this study, the depression decreased significantly in the experimental group, but in the control group, the level of depression slightly increased. There was statistical difference between the two groups. This result was similar to the following two advanced researches. The study by No [24] showed that giving stroke patients a rhythmic program decreased the feeling of burden. The other study by Park and Park [16] showed that emotional and informational support positively affected the family members with stroke patients and there was also a significant decrease in the experimental group. However it is stated in the study by Kong and Lee [25] that there was a decrease in the level of depression after the empowerment program but there was no statistical difference between the two groups. Thus it seems that providing the rehabilitation education program is effective at relieving the level of depression significantly.

Even though family caregivers of stroke patients demand sufficient support for rehabilitation in a clinical field, there is a lack of appropriate information and support. Since the way to acquire appropriate information is limited, their feeling of burden is considered immense.

Consequently, the family caregivers with stroke patients want to grasp the exact idea about the stroke and to be provided with appropriate support. So it is considered that more effective rehabilitation program by physical therapists needs to be developed in order to generate positive effects on the ability of nursing the patients and the knowledge of the stroke. This will lead to improvement of the nursing quality of family caregivers and relief of the feeling of burden and depression.

The limitations of this study are inadequate number of participants and the difficulty to generalize and control participants' daily living. Also, 4 weeks of intervention was not sufficient to point out the variation of psychological dependent variable and the later examination to check the long-term effect was not carried out. Therefore, to demonstrate the general effect of the rehabilitation program, sufficient number of participants and long-term study are necessary. Our study suggests that the rehabilitation education program is effective at decreasing the level of burden and depression. Furthermore, the program will make a positive effect on the patients' quality of life as well as the result of therapy. 


\section{References}

[1] Korea National Statistical Office. 2010[Internet]. Daejeon: National Statistical Office; 2010. Available from: http://kostat.go.kr

[2] Biegel DE, Sales E, Schulz R. "Family Caregiving in Chronic Illness: Alzheimer's disease, cancer, heart disease, mental illness, and stroke." Thousand Oaks, CA, US: SAGE Publications, Inc.;1991

[3] You KS. "A study on the care burden of family caregivers for senile dementia." J Korea Community Health Nurs Acad Soc, 2001;15(1):125-147.

[4] Van den Heuvel ET, de Witte LP, Nooyen-Haazen I, Sanderman R, Meyboom-de Jong B. "Short-term effects of a group support program an individual support program for caregivers of stroke patients." Patient Educ Couns. 2000 May;40(2):109-20.

[5] Han B, Haley WE. "Family Caregiving for Patients with stroke review and analysis." Stroke, 1999;30(7):1478-1485.

[6] Wade DT, Legh-Smith J, Hewer RL. "Effect of living with and looking after survivors of stroke." Br Med J (Clin Res Ed), 1986;293(6544): 418-420.

[7] Beck AT. "The development of depression: a cognitive model. The psychology of depression : contemporary thepory and research." Oxford, England: John Wiley and Sons Inc.;1974.

[8] Baillie V, Norbeck JS, Barnes LE. "Stress, social support a psychological distress of family caregivers of the elderly." Nurs Res 1988;37(4):217-222.

[9] Deimling G, Bass D. "Symptoms of mental impairment among elderly adults and their effects on family caregivers." J Geron, 1986;41:778-784.

[10] Park YH, You SJ, Song MS. "Caregiver Burden of Families with Stroke Patients and their Needs for Support Group Intervention." J Korean Acad Adult Nurs, 1999;11(1):119-134.

[11] Anderson CS, Linto J, Stewart-Wynne EG. "A Population-Based Assessment of the Impact and Burden of Caregiving for Long term Stroke Survivors." Stroke 1995;26(5):848-849.

[12] Biegel DE, Sales E, Schulz R. "Family Caregiving in Chronic Illness: Alzheimer's disease, cancer, heart disease, mental illness, and stroke." Thousand Oaks, CA, US: SAGE Publications, Inc.;1991
[13] Chumbler NR, Rittman M, Van Puymbroeck M, Vogel WB, Qin H. "The sense of coherence, burden, and depressive symptoms in informal caregivers during the first month after stroke."Int J Geriatr Psychiatry 2004;19(10):944-53.

[14] Kang SJ, Lee HJ, Choi SM. "Caregiver's Burden in patients with acute stroke.” Korean J Rehabil Nurs 2002;5(1):27-37.

[15] Morimoto T, Schreiner AS, Asano H. "Caregiver burden and health-related quality of life among Japanese stroke caregivers." Age and Ageing, 2003;32(2):218-223.

[16] Park YS, Park HY. "The Effect of Emotional and informational support intervention on role stress and depression of primary family caregivers caring stroke patients." J Korea Community Health Nurs Acad Soc, 2001;15(1):96-110.

[17] Zarit SH. "Relatives of the impaired elderly: Correlates of feelings of burden." The Gerontologist. 1980;20(6):649-655

[18] Montgomery RJ, Gonyea JG, Hooyman NR. "Caregiving and the experience of subjective and objective burden." Family relations, 1985;34:19-26.

[19] Novak M, Guest C. "Application of a multidimensional caregiver Burden Inventory." The Gerontologist, 1989;29(6):798-803

[20] Suh MH, Oh KS. "A study of well-being in caregivers caring for chronically ill family members." JKAN 1993;23(3):467-486.

[21] Radloff LS. "The CES-D scale: A self-report depression scale or research in the general population.” Appl. Psychol. Meas, 1977;1(3):385-401.

[22] Kim MS, Park HS. "The Effect of Activity of Daily Living Exercise for Self-care Ability and Family Burden in Stroke Patients." Korean J Rehabil Nurs, 2005;8(2):165-174.

[23] Yoo EK, Jeon SH, Yang JE. "The Effects of a support group intervention on the burden of primary family caregivers of stroke patients." J Korean Acad Nurs, 2007;37(5):693-702

[24] No KH. "Effect of Rhythmic Exercise with Video Tape on Walking, Movement Balance, Depression, and Quality of Life.” Korean J Rehabil Nurs, 2003;6(1):70-78.

[25] Kong HK, Lee HJ. "Effect of Empowerment Program on Rehabilitation Motivation, Depression, Activities of Daily Living Among the Patients with Stroke." J Korean Geriatr Soc, 2008;20(3):406-417. 